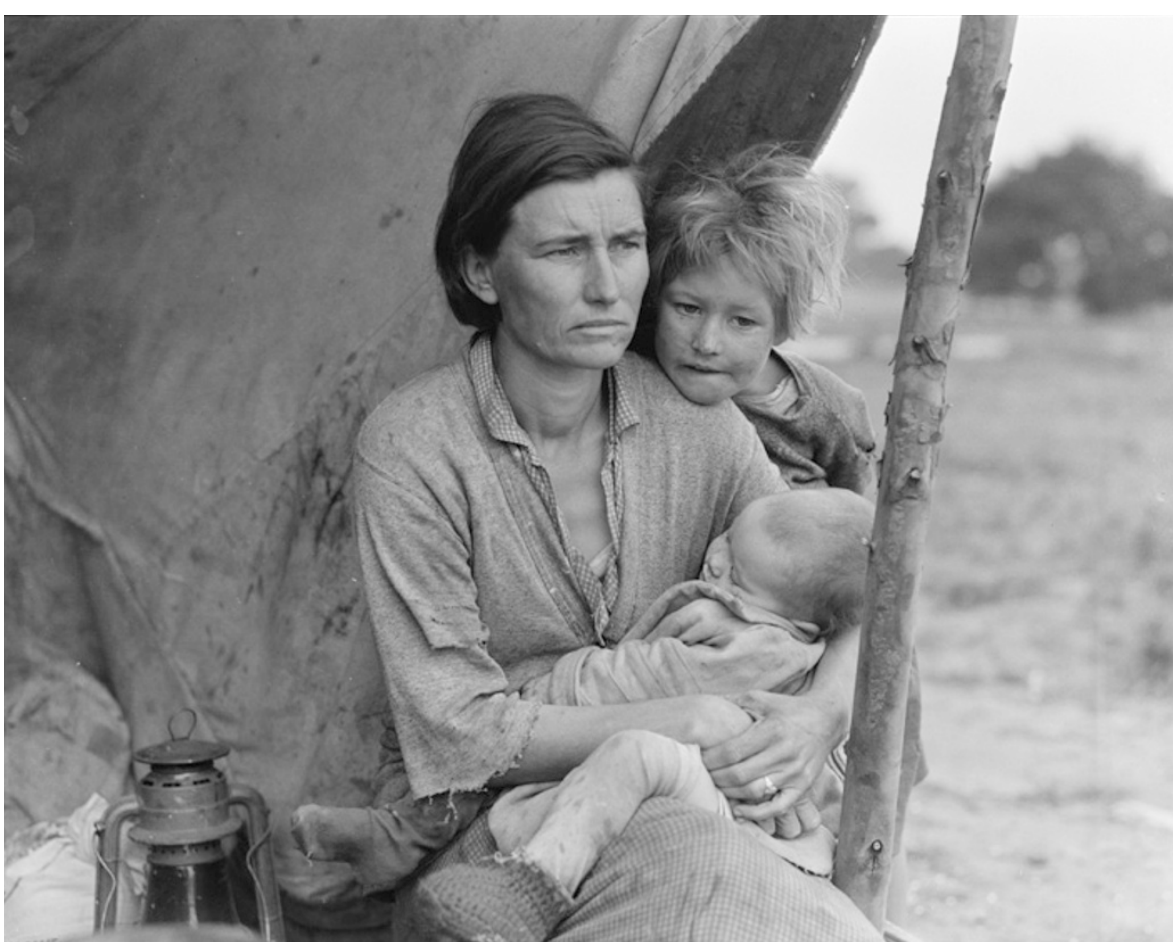

Hundreds of thousands fled the 1930s US Dust Bowl; more drought-spurred migrations are expected.

\title{
The next dust bowl
}

\section{Drought is the most pressing problem caused by climate change. It receives too little attention, says Joseph Romm.}

$\mathrm{W}$ hich impact of anthropogenic global warming will harm the most people in the coming decades? I believe that the answer is extended or permanent drought over large parts of currently habitable or arable land - a drastic change in climate that will threaten food security and may be irreversible over centuries.

A basic prediction of climate science is that many parts of the world will experience longer and deeper droughts, thanks to the synergistic effects of drying, warming and the melting of snow and ice.

Precipitation patterns are expected to shift, expanding the dry subtropics. What precipitation there is will probably come in extreme deluges, resulting in runoff rather than drought alleviation. Warming causes greater evaporation and, once the ground is dry, the Sun's energy goes into baking the soil, leading to a further increase in air temperature. That is why, for instance, so many temperature records were set for the United States in the 1930s Dust Bowl; and why, in
2011, drought-stricken Texas saw the hottest summer ever recorded for a US state. Finally, many regions are expected to see earlier snowmelt, so less water will be stored on mountain tops for the summer dry season. Added to natural climatic variation, such as the El Niño-La Niña cycle, these factors will intensify seasonal or decade-long droughts. Although the models don't all agree on the specifics, the overall drying trends are clear.

I used to call the confluence of these processes 'desertification' on my blog, ClimateProgress.org, until some readers pointed out that many deserts are high in biodiversity, which isn't where we're heading. 'Dustbowlification' is perhaps a more accurate and vivid term, particularly for Americans - many of whom still believe that climate change will only affect far-away places in far-distant times. Prolonged drought will strike around the globe, but it is surprising to many that it would hit the US heartland so strongly and so soon.

The coming droughts ought to be a major driver - if not the major driver - of climate policies. Yet few policy-makers and journalists seem to be aware of dust-bowlification and its potentially devastating impact on food security. That's partly understandable, because much of the key research cited in this article post-dates the 2007 Fourth Assessment Report of the Intergovernmental Panel on Climate Change (IPCC). Raising public awareness of, and scientific focus on, the likelihood of severe effects of drought is the first step in prompting action.

\section{AMERICAN NIGHTMARE}

I first heard of the risks in a 2005 talk by climatologist Jonathan Overpeck of the University of Arizona in Tucson. He pointed to emerging evidence that temperature and annual precipitation were heading in opposite directions over many regions and raised the question of whether we are at the "dawn of the super-interglacial drought”.

The idea wasn't new. As far back as 1990, scientists at NASA's Goddard Institute for Space Studies in New York projected that severe to extreme drought in the United States, then occurring every 20 years or so, could become an every-other-year phenomenon by mid-century ${ }^{1}$.

Events are starting to bear out these worrying predictions. Snowpack reduction, early snowmelt and a decrease in dry-season river flow in the American West, forecast more than two decades ago, have now been measured $^{2}$. In much of the northern Rockies, the peak of the annual stream runoff is up to three or four weeks earlier than it was half a century ago ${ }^{3}$. Heat and drought coupled with the greater impact of destructive species, such as bark beetles, aided by warming - have increased forest die-off and the risk of wildfire.

The palaeoclimate record dating back to the medieval period reveals droughts lasting many decades. But the extreme droughts that the United States faces this century will be far hotter than the worst of those: recent decades have been warmer than the driest decade of the worst drought in the past 1,200 years ${ }^{4}$.

And much warmer conditions are projected. According to a 2009 report of the US Global Change Research Program ${ }^{5}$, warming over mid-latitude land masses, such as the continental United States, is predicted to be higher than the forecast average global warming: much of the inland United States faces a rise of between $5^{\circ} \mathrm{C}$ and $6^{\circ} \mathrm{C}$ on the current emissions path (that is, 'business as usual') by the century's end, with a substantial fraction of that warming occurring by mid-century.

A 2007 analysis of 19 climate projections estimated that levels of aridity comparable to those in the Dust Bowl could stretch from 

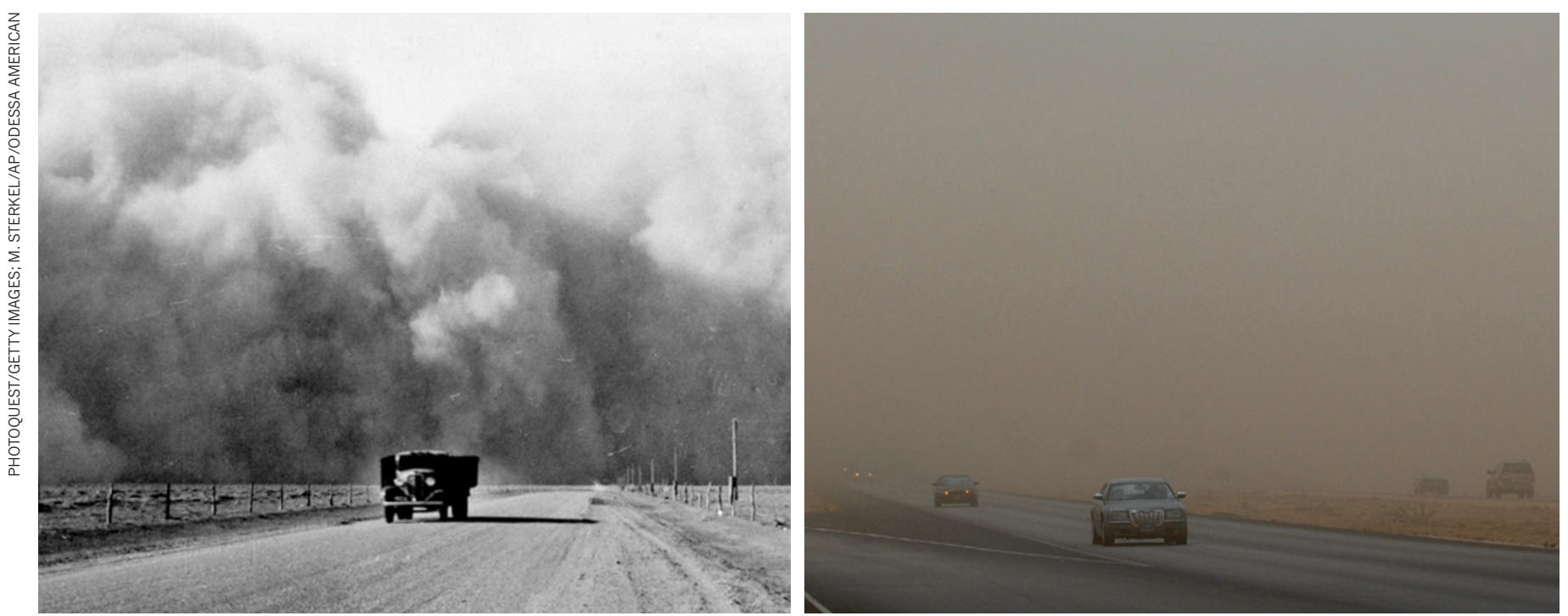

Then and now: sun-baked dry soils kick up clouds of dust in the 1930 s (left) and in the modern United States (right).

Kansas to California by mid-century ${ }^{6}$. To make matters worse, the regions at risk of reduced water supply, such as Nevada, have seen a massive population boom in the past decade. Overuse of water in these areas has long been rife, depleting groundwater stores.

Of course, the United States is not alone in facing such problems. Since 1950, the global percentage of dry areas has increased by about $1.74 \%$ of global land area per decade $^{7}$. Recent studies have projected 'extreme drought' conditions by mid-century over some of the most populated areas on Earth - southern Europe, south-east Asia, Brazil, the US Southwest, and large parts of Australia and Africa ${ }^{8}$. These dust-bowl conditions are projected to worsen for many decades and be "largely irreversible for 1,000 years after emissions stopped" ".

The concept of drought has not been ignored by the IPCC and other scientific groups; there is even a United Nations Convention to Combat Desertification. But the cumulative risks don't seem to have been fully recognized by the public and by policymakers. And key questions remain to be answered, ideally in a dedicated report by an organization such as the US National Academy of Sciences or the IPCC.

\section{UNANSWERED QUESTIONS}

Most pressingly, what will happen to global food security if dust-bowl conditions become the norm for both food-importing and foodexporting countries? Extreme, widespread droughts will be happening at the same time as sea level rise and salt-water intrusion threaten some of the richest agricultural deltas in the world, such as those of the Nile and the Ganges. Meanwhile, ocean acidification, warming and overfishing may severely deplete the food available from the sea.

What are the implications of dustbowlification for energy generation? After

agriculture, energy generation is responsible for the majority of freshwater withdrawals, and two key strategies for generating additional potable water - wastewater purification and desalinization - are both energy intensive. Future energy systems will need to be low on greenhouse-gas emissions and on water use. In particular, thermal power plants - including nuclear - may need to switch from evaporative or 'wet cooling'

"Aridity

comparable to

the 1930s Dust

Bowl could stretch from

Kansas to

California by mid-century." systems to dry cooling techniques, which, unfortunately, tend to be less efficient.

From an ecological perspective, what will be the effects of dustbowlification on the global carbon cycle? In the past six years, the Amazon has seen two droughts of the sort expected once in 100 years, each of which may have released as much carbon dioxide from vegetation dieoff as the United States emits from fossil-fuel combustion in a year. More frequent wildfires also threaten to increase carbon emissions. And as habitats are made untenable, what will be the effect on biodiversity?

At the same time, drought models need to be improved. They successfully chart the hydrological changes seen in the US Southwest and the drying seen at the global level ${ }^{7}$, but regional predictions can be disturbingly variable. Some models forecast an increase in precipitation for East Africa, whereas others correctly predicted in 2010 that warming of the Indian Ocean would lead to drought in the region, such as this year's devastating drought in Somalia. The models need higher resolution and a better understanding of precipitation, sea surface temperature and the effects of vegetation.

Human adaptation to prolonged, extreme drought is difficult or impossible. Historically, the primary adaptation to dust-bowlification has been abandonment; the very word 'desert' comes from the Latin desertum for 'an abandoned place'. During the relatively short-lived US Dust-Bowl era, hundreds of thousands of families fled the region. We need to plan how the world will deal with drought-spurred migrations (see page 447) and steadily growing areas of nonarable land in the heart of densely populated countries and global bread-baskets. Feeding some 9 billion people by mid-century in the face of a rapidly worsening climate may well be the greatest challenge the human race has ever faced.

These predictions are not worst-case scenarios: they assume business-as-usual greenhouse-gas emissions. We can hope that the models are too pessimistic, but some changes, such as the expansion of the subtropics, already seem to be occurring faster than models have projected ${ }^{10}$. We clearly need to pursue the most aggressive greenhouse-gas mitigation policies promptly, and put dustbowlification atop the world agenda.

Joseph Romm is a physicist who edits the blog ClimateProgress.org for the Center for American Progress Action Fund, Washington DC, USA.

e-mail:jromm@americanprogress.org

1. Rind, D. et al. J. Geophys. Res. 95, 9983-10004 (1990).

2. Barnett, T. P. Science 319, 1080-1083 (2008).

3. Stewart, I. T. et al. J. Climate 18, 1136-1154 (2005).

4. Woodhouse, C. A. et al. Proc. Natl Acad. Sci. USA 107, 21283-21288 (2010)

5. Global Climate Change Impacts in the U.S. (USGCRP/Cambridge Univ. Press, 2009).

6. Seager, R. et al. Science 316, 1181-1184 (2007).

7. Dai, A. J. Geophys. Res. 116, D12115 (2011).

8. Dai, A. Climate Change 2, 45-65 (2011).

9. Solomon, S. et al. Proc. Natl Acad. Sci. USA 106, 1704-1709 (2009)

10.Seidel, D. J. et al. Nature Geosci. 1, 21-24 (2008). 